University of South Carolina

Scholar Commons

1987

\title{
Modeling the Rotating Disk Electrode for Studying the Kinetics of Electrochemical Reactions
}

\author{
P K. Adanuvor \\ Texas A \& M University - College Station \\ Ralph E. White \\ University of South Carolina - Columbia, white@cec.sc.edu
}

S E. Lorimer

Follow this and additional works at: https://scholarcommons.sc.edu/eche_facpub

Part of the Chemical Engineering Commons

\section{Publication Info}

Journal of the Electrochemical Society, 1987, pages 625-631.

(c) The Electrochemical Society, Inc. 1987. All rights reserved. Except as provided under U.S. copyright law, this work may not be reproduced, resold, distributed, or modified without the express permission of The Electrochemical Society (ECS). The archival version of this work was published in Journal of the Electrochemical Society.

http://www.electrochem.org/

DOI: $10.1149 / 1.2100519$

Publisher's Version: http://dx.doi.org/10.1149/1.2100519

This Article is brought to you by the Chemical Engineering, Department of at Scholar Commons. It has been accepted for inclusion in Faculty Publications by an authorized administrator of Scholar Commons. For more information, please contact digres@mailbox.sc.edu. 


\title{
An Analysis of a Back Fed Porous Electrode for the $\mathrm{Br}_{2} / \mathrm{Br}$ Redox Reaction
}

\author{
John Van Zee* and Ralph E. White** \\ Department of Chemical Engineering, Texas A\&M University, College Station, Texas 77843
}

\section{ABSTRACT}

An experimental analysis of the $\mathrm{Br}_{2} / \mathrm{Br}^{-}$redox reaction in a porous back fed ruthenium-coated titanium electrode is described. A mathematical model of the steady-state process is presented. Nonlinear regression of the model against the experimental data gives physically meaningful parameter estimates; these parameters and the model provide a design equation for the porous electrode current as a function of specific surface area, bulk $\mathrm{Br}_{2}$ concentration, average total overpotential, and the Reynolds number. The design equation shows that the back fed electrode could reduce the loss of $\mathrm{Br}_{2}$ across the separator and the ohmic loss in a $\mathrm{Zn} / \mathrm{Br}_{2}$ battery.

A flow-by back fed porous electrode, as shown in Fig. 1 , is a diffusion electrode. The term "flow-by" emphasizes that the reactant flows outside rather than through the electrode. Consequently, fresh reactant must diffuse to a reaction site within the porous electrode. Typically, the reaction occurs on the side closest to the counterelectrode if the catalyst application and the concentration are uniform. Thus, the back fed electrode may be limited by diffusion if it is too thick. This may be the reason it has been ignored by commercial monopolar $\mathrm{Zn} / \mathrm{Br}_{2}$ battery designers $(1,2)$.

However, this back fed configuration may provide some advantages for a $\mathrm{Zn} / \mathrm{Br}_{2}$ battery or similar electrochemical system. Specifically, the back fed electrode may reduce the ohmic energy loss and the product (e.g., $\mathrm{Br}_{2}$ ) loss across the separator. The ohmic energy loss would be decreased because the solution gap between the electrodes would be reduced to approximately half that of the front fed electrode (compare Fig. 1 and 2). This reduction in electrode gap could decrease the cell's specific resistance by more than $25 \%$ in $\mathrm{Zn} / \mathrm{Br}_{2}$ batteries if a relatively nonconducting complexing agent (3) is present in the electrolyte. [This decrease in resistance is approximately $25 \%$ because the electrolyte between the electrodes contributes only approximately $50 \%$ of the ohmic loss in a $\mathrm{Zn} / \mathrm{Br}_{2}$ battery $(1,4)$.] The same percentage decrease might be observed in gas generating cells. The loss of product across the separator may be reduced because the porous electrode may act as a separator when the reaction occurs preferentially on the back side (fresh solution side) of the porous electrode (Fig. 1). This reduction of the product loss across the separator would probably decrease the self-discharge rate in a $\mathrm{Zn} / \mathrm{Br}_{2}$ battery.

Even though back fed electrodes are limited by diffusion, the limiting current due to diffusion may be adequate for the specific application. This is evident, for example, in the back fed electrode designs of SPE water electrolyzers (5) where the diffusion limiting current is large because the reactant is in abundance. Even if the reactant is present in low concentration, the process may be limited to some current below the diffusion limited current by slow kinetics or by some other feature of the other electrode. For example, in $\mathrm{Zn} / \mathrm{Br}_{2}$ batteries the $\mathrm{Br}_{2}$ electrode is not required to operate above $50 \mathrm{~mA} / \mathrm{cm}^{2}$ because of zinc dendrite formation at the zinc electrode $(1,2,4,6,7)$.

Since the design principles for flow-by back fed porous electrodes are not well known, this paper presents an analysis of this electrode design for the bromine/bromide reaction

$$
\mathrm{Br}_{2}+2 e^{-} \rightarrow 2 \mathrm{Br}^{-}
$$

- Electrochemical Society Student Member

- Electrochemical Society Active Member.

Key words: battery, current density, mass transport, kinetics.
First, a mechanistic model of the steady-state process is developed. Next, an experimental study of the bromine/bromide redox reaction is presented. Then, least squares regression techniques are used to fit the model to experimental data to obtain physically meaningful parameter estimates. Finally, the regression results and the mechanistic model are used to analyze the physical behavior of a flow-by back fed porous $\mathrm{Br}_{2}$ electrode.

\section{Previous Work}

The previous analyses (8-12) of steady-state mass transfer in porous diffusion electrodes pertinent to the back fed model developed below have been reviewed by Newman and Tiedeman (13).1 In these previous

${ }^{1}$ The approach of these analyses differs from the approach of single-pore models (see Ref. (14), for example) as described by Tilak et al. (15) because it uses a pseudo-homogeneous reaction rate and volume average quantities instead of the single-pore concept.

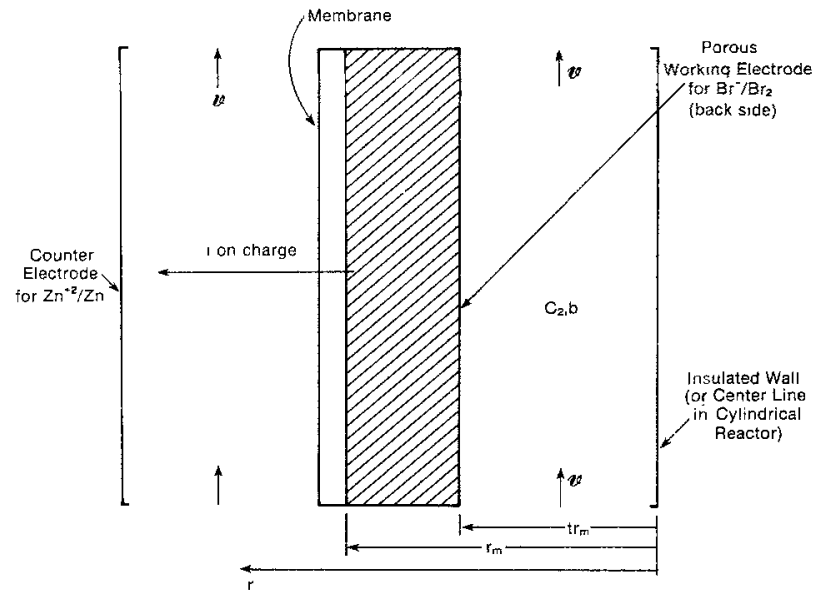

Fig. 1. A schematic of a back fed porous electrode for the bromine/bromide redox reaction in a $\mathrm{Zn}_{\mathbf{n}} / \mathrm{Br}_{\mathbf{Z}}$ battery.

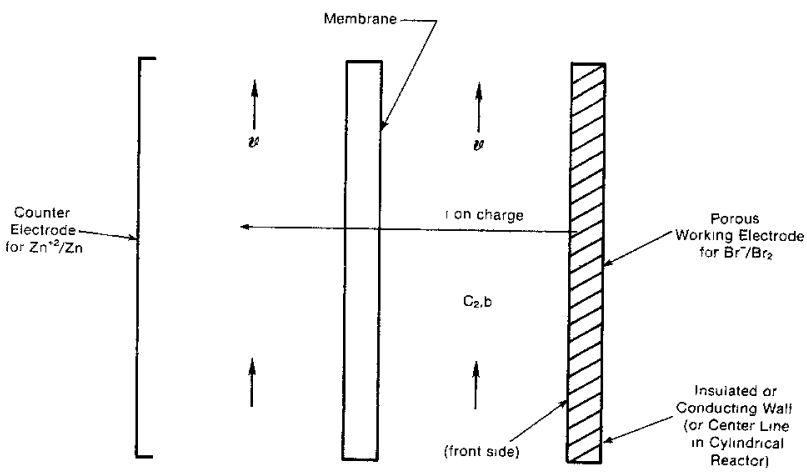

Fig. 2. A schematic of a front fed porous electrode 
analyses, the authors have considered redox reactions which have stoichiometric coefficients of +1 and -1 for anodic and cathodic species, respectively, whereas the coefficients used here are +2 and -1 as shown by reaction [1]. These previous models and the model developed here include the assumption of excess supporting electrolyte and, consequently, neglect the effect of ionic migration. The boundary conditions for the concentration in the previous analyses require a known constant concentration of reactant at the edge of the porous region whereas in the model developed below the reactant concentration at the edge of the porous region depends on overpotenial, Reynolds number, and the bulk properties of the flowing electrolyte.

The results most closely related to the back fed electrode model presented here are those of Newman and Tiedeman (13) and Austin and Lerner (12) because they neglect the ohmic potential drop in both the matrix and the solution and because they use a complete Butler-Volmer kinetic expression. Newman and Tiedeman (13) give the current/potential relationship in Cartesian coordinates for redox reactions with stoichiometric coefficients of +1 and -1 and a constant concentration at the reservoir-electrode interface. One problem with this fixed concentration boundary condition model is that accurate predictions of the current density from the resulting equations occur only for infinitely large rates of external mass transfer. Austin and Lerner (12) use a stagnant film concept to relax the constant concentration boundary condition and, thereby, include the effect of external mass transport; they show the current potential relationship in Cartesian coordinates in terms of the limiting current. The limiting current density in Ref. (12) could have been but was not given as a function of the external mass transfer coefficient

$$
i_{\mathrm{L}}=k c_{\mathrm{i}, \mathrm{b}} \frac{n \mathbf{F}}{\mathrm{s}_{\mathrm{j}}}
$$

This mass transfer coefficient $k$ is included in the back fed model developed below. Austin and Lerner (12) discuss the relative importance of the ohmic drop in the solution phase and they show that its neglection may be a reasonable assumption when the reaction occurs over a very short distance as is the case for the model presented here as discussed below.

\section{Model}

The model developed here extends similar developments for steady-state mass transfer in porous electrodes (8-13) by including an external mass transfer coefficient and different stoichiometric coefficients for the reactant and product. That is, redox reactions considered in Ref. (8-13) have stoichiometric coefficients of +1 and -1 for the oxidized and reduced species, respectively, whereas the coefficients used here are +2 and -1 as shown by reaction [1].

The model is presented by first stating the assumptions and then developing the equations. The assumptions used in the development of the model are

a. Steady-state is maintained.

b. The porosity and specific catalytic surface area are uniform and they do not change with time.

c. Dilute solution theory (13) applies.

d. Sufficient supporting electrolyte exists so that ionic migration can be neglected (i.e., no potential drop in the solution).

e. Dispersion and convection are not present in the porous section of the electrode.

f. In the porous region, the only important gradients are those in the direction normal to the fluid flow.

g. The separator at the edge opposite the flowing solution is impermeable to the reacting species.

h. The hydrodynamic profile is known in the nonporous region.

i. The potential drop in the matrix is negligible. j. The concentration of the anodic reactant, $\mathrm{Br}^{-}$, is large relative to the concentration of the cathodic reactant, $\mathrm{Br}_{2}$.

$k$. The kinetic expression follows a Butler-Volmer type expression where the cathodic reaction order is unity and reaction $\lfloor 1\rfloor$ is assumed to be an elementary step.

1. Isothermal conditions exist.

$m$. The conversion per pass is small.

These assumptions permit the development of a single analytical expression suitable for design over a large range of overpotentials.

The equations of this model can be developed by considering the cylindrical back fed electrode of Fig. 1. (Cylindrical coordinates are used since the experimental data were obtained with a tubular porous electrode.) Bromine is present at a concentration of $c_{2, b}$ in the stream having an axial velocity $v$. The redox reaction of interest here occurs in the porous electrode which has an outside radius of $r_{m}$ and an inside radius of $t r_{\mathrm{m}}$ where $t$ is less than one.

The steady-state material balance for the $i^{\text {th }}$ species within the porous electrode can be written as (13)

$$
-\nabla \cdot N_{i}+a j_{i}=0
$$

for reaction [1] with subscript i equal to 1 and 2 for $\mathrm{Br}^{-}$and $\mathrm{Br}_{2}$, respectively. The volume average production rate $a j_{1}$ can be written as (16)

$$
\begin{aligned}
a j_{\mathrm{i}}=\frac{-s_{\mathrm{i}} a i_{\mathrm{o}, \mathrm{b}}}{n \mathbf{F}} & \left\{\prod_{i}\left(\frac{c_{\mathrm{i}}}{c_{\mathrm{i}, \mathrm{b}}}\right)^{\mathrm{p}_{1}} \exp \left(\frac{\alpha_{\mathrm{a}} \mathbf{F}}{R T} \eta\right)\right. \\
& \left.-\prod_{i}\left(\frac{c_{\mathrm{i}}}{c_{\mathrm{i}, \mathrm{b}}}\right)^{\mathrm{q}_{1}} \exp \left(\frac{-\alpha_{\mathrm{c}} \mathbf{F}}{R T} \eta\right)\right\}
\end{aligned}
$$

where

$$
\begin{gathered}
i_{0, b}=i_{0} \circ \prod_{i}\left(\frac{c_{i, b}}{c_{i} \circ}\right)^{\gamma_{1}} \\
p_{i}=\gamma_{i}+\frac{\alpha_{\mathrm{a}} s_{i}}{n} \\
q_{i}=\gamma_{i}-\frac{\alpha_{c} s_{1}}{n}
\end{gathered}
$$

and

$$
\begin{gathered}
\alpha_{\mathrm{a}}+\alpha_{\mathrm{c}}=n \\
\eta=V-\Phi_{2}-\Delta U_{\mathrm{b}}
\end{gathered}
$$

The reaction orders $p_{i}$ and $q_{i}$ in Eq. [4] can be related to the stoichiometry for an elementary step (17): (i) for anodic reactants, $p_{i}=s_{1}$ and $q_{i}=0$ and (ii) for cathodic reactants, $q_{i}=-s_{i}$ and $p_{i}=0$. The concentration dependence on the exchange current density of species $i, \gamma_{i}$, is then related simply to the stoichiometric equation. That is, since reaction [1] is assumed to be an elementary step and if it is assumed that $\alpha_{\mathrm{a}}=\alpha_{\mathrm{c}}=1.0$, for example, then

$$
\gamma_{1}=2-\frac{(1.0)(2)}{2}=1.0
$$

and

$$
\gamma_{2}=1+\frac{(1.0)(-1)}{2}=0.5
$$

The total overpotential $\eta$ in Eq. [4] and [9] is the sum of the surface overpotential and the local overpotential from outside the double layer to the bulk solution. This overpotential includes the effect of a reference electrode which differs from the working electrode by the term $\Delta U_{\mathrm{b}}$ where

$$
\begin{aligned}
\Delta U_{\mathrm{b}}=U^{\theta}-U_{\mathrm{re}}{ }^{\theta} & -\frac{R T}{n \mathbf{F}} \sum_{i} s_{\mathrm{i}} \ln \left(\frac{c_{\mathrm{i}, \mathrm{b}}}{\rho_{\mathrm{o}}}\right) \\
& +\frac{R T}{n_{\mathrm{re}} \mathbf{F}} \sum_{i} s_{\mathrm{i}, \mathrm{re}} \ln \left(\frac{c_{\mathrm{i}, \mathrm{re}}}{\rho_{\mathrm{o}}}\right)
\end{aligned}
$$


It is important to note that both $i_{0, b}$ and $\Delta U_{\mathrm{b}}$ are based on the same bulk concentration $\left(c_{2, b}\right)$, and that the potential of the working and reference electrodes must be referenced to the same thermodynamic scale (e.g., $\mathrm{H}_{2}$ scale).

Neglecting ionic migration according to Assumption $d$, the specitic expression tor the flux of $\mathrm{Br}_{2}$ in the porous eiectrode is

$$
N_{2}=-D_{\theta} \frac{d c_{2}}{d r}
$$

where solution in terms of modified Bessel functions of the first and second kind (19). The complete solution to Eq. [18] is [see Ref. (20)]

$$
\begin{aligned}
\theta(\xi)=G[\theta(t) & -1.0]\left\{\frac{K_{1}(\sqrt{B})}{I_{1}(\sqrt{\bar{B}})} I_{0}(\sqrt{B} \xi)\right. \\
& \left.+K_{0}(\sqrt{\bar{B} \xi})\right\}+\exp \left(\frac{2 F}{R T} \eta\right)
\end{aligned}
$$

where the dimensionless surface concentration is

$$
\begin{gathered}
\theta(t)=\frac{G K_{1}(\sqrt{B}) I_{0}(\sqrt{B} t)+G I_{1}(\sqrt{B}) K_{0}(\sqrt{B} t)-I_{1}(\sqrt{B}) \exp \left(\frac{2 F}{R T} \eta\right)}{G K_{1}(\sqrt{\bar{B}}) I_{0}(\sqrt{B} t)+G I_{1}(\sqrt{\bar{B}}) K_{0}(\sqrt{\bar{B}} t)-I_{1}(\sqrt{\bar{B}})} \quad \text { and } \\
D_{\mathrm{e}}=\frac{e}{\tau} D_{2} \quad[14] \quad G=\frac{r_{\mathrm{m}} k I_{1}(\sqrt{\bar{B}})}{D_{\mathrm{e}} \sqrt{\bar{B}}\left[K_{1}(\sqrt{\bar{B}}) I_{1}(\sqrt{\bar{B}} t)-I_{1}(\sqrt{\bar{B}}) K_{1}(\sqrt{\bar{B}} t)\right]}
\end{gathered}
$$

Substitution of Eq. [4], [13], and [14] into the radial component of the cylindrical form of Eq. [3] yields

$$
\frac{\mathrm{d}^{2} c_{2}}{d r^{2}}+\frac{1}{\mathrm{r}} \frac{d c_{2}}{d r}-K c_{2}=\frac{-a i_{\mathrm{o}, \mathrm{b}}}{2 \mathbf{F} D_{\mathrm{e}}} \exp \left(\frac{\alpha_{\mathrm{a}} \mathbf{F}}{R T} \eta\right)
$$

where

$$
K=\frac{a i_{0, \mathrm{~b}}}{2 \mathbf{F} D_{\mathrm{e}} \mathrm{c}_{2, \mathrm{~b}}} \exp \left(\frac{-\alpha_{\mathrm{c}} \mathbf{F}}{R T} \eta\right)
$$

and the local concentration of $\mathrm{Br}^{-}$has been assumed to be constant and equal to the bulk concentration of $\mathrm{Br}^{-}$, according to Assumption $\mathrm{j}$ (i.e., $c_{1} / c_{1, b}=1.0$ ).

The following dimensionless variables can be used to simplify Eq. [15]

$$
\varepsilon=\frac{r}{r_{m}}, \quad \theta=\frac{c_{2}}{c_{2, b}}
$$

which when substituted into Eq. [15] yields

$$
\frac{d^{2} \theta}{d \xi^{2}}+\frac{1}{\xi} \frac{d \theta}{d \xi}-B \theta=-A
$$

where

$$
B=K r_{m^{2}}
$$

and

$$
A=\frac{a i_{0, b} r_{m}^{2}}{2 F D_{\mathrm{e}} c_{2, b}} \exp \left(\frac{a_{\mathrm{a}} \mathbf{F}}{R T} \eta\right)
$$

Following Assumptions $\mathrm{g}, \mathrm{h}$, and $\mathrm{m}$, the boundary conditions are at

$$
r=r_{m}, \quad \xi=1 \quad \frac{d \theta}{d \xi}=0
$$

at

$$
r=r_{\mathrm{m}} t, \quad \xi=t \quad \frac{d \theta}{d \xi}=\frac{r_{\mathrm{m}} k}{D_{\mathrm{e}}}(\theta(t)-1.0)
$$

where the gradients are defined to be in the positive direction of $\xi$. The mass transfer coefficient $k$ in Eq. [22] is an average value over the length of the tubular reactor and is given by (18)

$$
k=1.651 \frac{D_{2}}{2 r_{\mathrm{i}}}\left(N_{\mathrm{Re}} N_{\mathrm{Se}} \frac{2 r_{1}}{L}\right)^{1 / 3}
$$

Equation [18] can be solved analytically by assuming a solution of the form

$$
\theta(\xi)=\Psi(\xi)+\Gamma
$$

where $\Gamma$ is a constant for a given $\eta$ and temperature and is given by

$$
r=\exp \left(\frac{2 F}{R T} \eta\right)
$$

Application of the boundary conditions, Eq. [21] and [22], to the homogeneous part of Eq. [18] gives the
An expression for the current density, consistent with the sign convention that cathodic currents are negative, can be obtained from the dimensional definition of the flux at the inside edge of the porous electrode

$$
\frac{i}{2 \mathbf{F}}=\left.N_{2}\right|_{\xi=\mathrm{t}}=k c_{2, \mathrm{~b}}[\theta(t)-1.0]
$$

In addition, the cross-sectional area at the inside edge of the porous electrode can be used to obtain an expression for the total current

$$
I=4 \pi t r_{\mathrm{m}} L \mathbf{F} k c_{2 . b}[\theta(t)-1.0]
$$

Equation [30] can be used to predict the current being passed by a back fed cylindrical porous electrode as a function of the applied potential and the Reynolds number because it includes the dependence of the concentration distribution on the mass transfer coefficient external to the porous electrode. Also, this equation applies to a front fed configuration where the separator and the counterelectrode are located at some radial position less than $t r_{m}$ (i.e., close to the center line). Thus, the orientation of the coordinate system would be the same as with the back fed electrode and therefore the boundary conditions of Eq. [21] and [22] would still apply. Conceptually, the boundary condition at $\xi=1$ would be the same because a backing plate would be considered impermeable. In this front fed configuration, the mass transfer coefficient must be adjusted for flow in an annulus (18). (Analogous equations for Cartesian coordinates are shown in the Appendix).

Equation [30] and the model presented here are limited to small conversions per pass because they include the lumped mass transfer coefficient of Eq. [23] (18). However, a small conversion per pass is a reasonable assumption for flow batteries (e.g., $\mathrm{Zn} / \mathrm{Br}_{2}$, $\mathrm{Zn} / \mathrm{Cl}_{2}$, redox) because large concentration changes occur only after many passes. Thus, the model has utility for flow batteries. Also, the model can be utilized to determine kinetic and mass transfer parameters from a reactor built to satisfy Assumption m; the parameters obtained from this differential reactor (laboratory scale) could then be used to design a more complicated pilot plant scale reactor.

A simple form of Eq. [27] for use in Eq. [30] can be obtained for the case where the pseudo-homogeneous rate constant $B$ is large and the electrode is not too thin; that is, for the cases where

$$
\sqrt{B} \geq 88 \text { and } t \leq 0.95
$$

Equation [27] becomes 


$$
(t)=\frac{k r_{\mathrm{m}}+D_{\mathrm{e}} \sqrt{\bar{B}} \exp \left(\frac{2 \mathbf{F}}{R T} \eta\right)}{k r_{\mathrm{m}}+D_{\mathrm{e}} \sqrt{\bar{B}}}
$$

or

$$
\theta(t)=\frac{1+P \exp \left(\frac{2 F}{R T} \eta\right)}{1+P}
$$

where

$$
P=\sqrt{\frac{D_{\mathrm{e}} a i_{0, \mathrm{~b}} \exp \left(\frac{-\alpha_{\mathrm{c}} \mathbf{F}}{R T} \eta\right)}{k^{2} 2 \mathrm{Fc}_{2, \mathrm{~b}}}}
$$

The dimensionless parameter $P$ in Eq. [34] shows the combined effects of internal, external, and charge transfer resistance on the surface concentration.

\section{Experimental Analysis}

The experimental analysis of the flow-by back fed cylindrical porous electrode considered the reduction of bromine to bromide according to Eq. [1] and the oxidation of bromide to bromine according to the reverse reaction of Eq. [1]. The experimental data were obtained by potentiostatic determination of the current for a cylindrical flow-by back fed porous Ti-RuO electrode. The dependent variable was the observed steady-state current and the independent variables were applied potential $\left(V-\Phi_{\mathrm{re}}\right)$ and the electrolyte flow which was equivalent to the Reynolds number $\left(N_{\mathrm{Re}}\right.$ ) since $\nu$ and $r_{\mathrm{i}}$ were assumed to be constant. The experiments were performed at a constant bulk $\mathrm{Br}_{2}$ concentration $\left(c_{2, b}\right)$ at different applied potentials and Reynolds numbers. The order of the experiments (i.e., the order for applying different values of the potential) was randomized to remove the effect of any concentration changes with time. This randomization insured that the experimental errors were independent and therefore the data are consistent with the assumptions of the least squares theory discussed below [see also, e.g., Ref. (21) ].

\section{Experimental Apparatus}

Reactor system.-A schematic of the reactor system is shown in Fig. 3; the negative electrolyte contacted the zinc terminal (i.e., the counterelectrode in this study) and the positive electrolyte contacted the

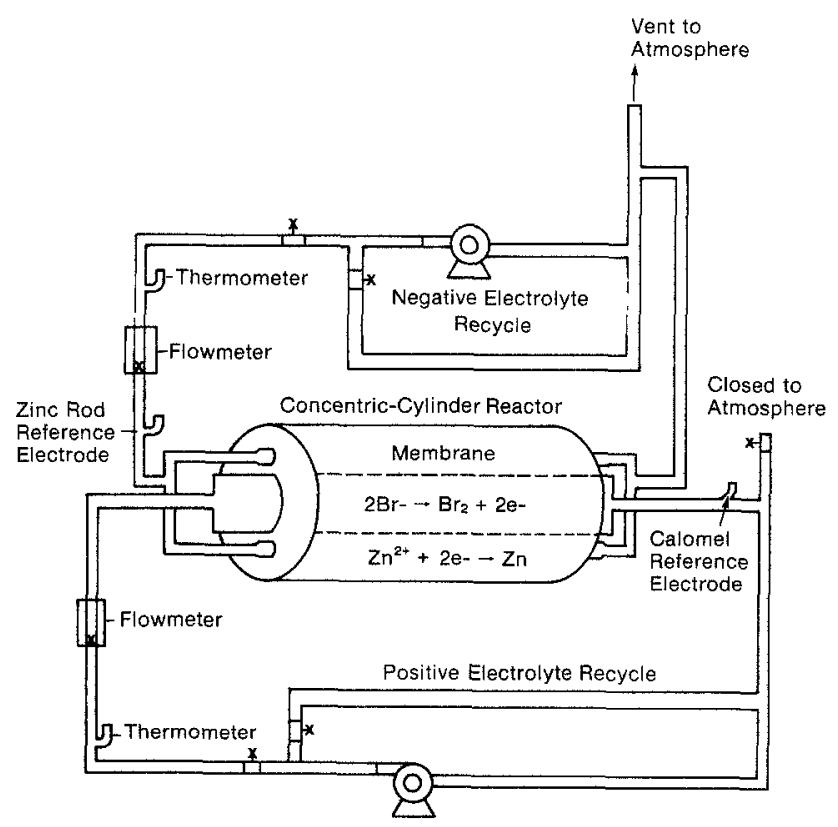

Fig. 3. A schematic of the experimental reactor system shown in the charge mode.
$\mathrm{Br}_{2} / \mathrm{Br}^{-}$terminal (i.e., the back fed porous working electrode under investigation here). Fisher flowmeters (No. 448-324) with $0.635 \mathrm{~cm}$ outside diameter glass floats were used for volumetric flow measurement. Constant speed magnetic induction centrifugal pumps (Eastern No. MD-15T-G01) were used to circulate the electrolytes; peristaltic (i.e., roller) pumps were not used because of reported problems with the surges in pressure caused by the rollers (22). The recycle streams were a necessary result of the constant speed pumps and they formed the reservoir for each electrolyte. Schedule 40, $1.27 \mathrm{~cm}$ PVC pipe was used for the system piping and smaller connections were made with Tygon tubing and hose clamps. Some attack of the tubing by $\mathrm{Br}_{2}$ was noticed over the life of the experiments ( $\sim 2$ months), but no loss of catalytic activity due to organic poisoning of the $\mathrm{Br}_{2}$ electrode by any dissolved Tygon was observed.

The experimental system was designed as shown in Table I, to be consistent with Assumptions $d, \dot{i}, j$, and $m$ used in the development of the theoretical model; the system was also designed in a manner similar to existing $\mathrm{Zn} / \mathrm{Br}_{2}$ batteries $(1,2,4,6,7,22)$. The experimental electrolyte was supported wtih excess $\mathrm{Na}^{+}$ to satisfy Assumption d. Although the specific conductivity $k$ of the electrolyte was not measured, it was probably about $0.4 \Omega^{-1} \mathrm{~cm}^{-1}(1,4)$. Using this $k$ value, the voltage drop in the solution over the length of a reaction zone on the order of $10^{-2} \mathrm{~cm}$ can be calculated by Ohm's law and shown to be on the order of $10 \mathrm{mV}$ (20) at a current density of $50 \mathrm{~mA} / \mathrm{cm}^{2}$ (a small reaction zone is expected for this fast reaction as described below); this voltage drop is consistent with part of Assumption $i$. The concentration of bromide in Table I is approximately 80 times larger than the limiting reactant, bromine. This concentration ratio is consistent with existing $\mathrm{Zn} / \mathrm{Br}_{2}$ battery design and Assumption $\mathbf{j}$. Table I also shows that the conversion (or production) per pass of bromine is expected to be low for typical currents and Reynolds numbers, as discussed below.

Electrodes.-The zinc terminal (i.e., counterelectrode) consisted of a $2.54 \mathrm{~cm}$ OD titanium tube with a wall thickness of $0.125 \mathrm{~cm}$. The negative electrolyte was fed to the inside of the tube through PVC end caps. The end caps fit snugly over the outside of the titanium tube and small leaks were stopped by wrapping Teflon tape around the outside of the tube. The inner electrode hole in the center of the end caps was sealed with an O-ring and the end cap lids. Two equally spaced electrical connections were made between the end caps; no measurable voltage drop existed between the connections or over the length of the counterelectrode. During the anodic or charge mode of the experiment, bromide was oxidized to bromine and zinc was plated at this counterelectrode. Conversely, when cathodic potentials were applied, bromine was reduced to bromide at the porous electrode and zinc was dissolved at the counterelectrode.

Table 1. Experimental system design specifications

Negative electrolyte volume

Positive electrolyte volume

Negative electrolyte composition:

$\mathrm{ZnBr}$

pH (lowered from 3.8 with HBr)

pyonil

Positive electrolyte compasition:

$\mathrm{ZnBr}$

$\mathrm{NaBr}$

Bri

Negative and positive electrolyte density at $22^{\circ} \mathrm{C}$

Electrode length

Counterelectrode plating area

Annulus spacing

Positive electrode outside diameter $\left(2 r_{\mathrm{m}}\right)$

Positive electrolyte, cathodic reactant conversion

per pass for $N \mathrm{Re}=100$ and $0.25 \mathrm{~A}$ (assuming

$100 \%$ faradaic conversion)
$420 \pm 10 \mathrm{~cm}^{3}$ $420 \pm 10 \mathrm{~cm}^{\mathrm{s}}$
$580 \pm 10 \mathrm{~cm}^{\mathrm{s}}$

$1.05 \mathrm{M}$

2.08

100 ppm

$1.05 \mathrm{M}$

$2.08 \mathrm{M}$

0.0510

$1.38 \mathrm{~g} / \mathrm{cm}^{\mathrm{s}}$

$12.7 \mathrm{~cm}$

$56.2 \mathrm{~cm}^{2}$

$0.4572 \mathrm{~cm}$

$8.0 \%$ 
The flow-by back fed electrode (again, the experimental working electrode) consisted of a titanium tube perforated with 400 holes which were drilled with a No. 57 drill $(0.10922 \mathrm{~cm}$ diam $)$. The titanium tube wall thickness was $0.0889 \mathrm{~cm}$ and the outside diameter of the tube was $0.635 \mathrm{~cm}$. The entire tube was coated with $\mathrm{RuO}_{2}$ by using a standard dimensionally stable anode (DSA) preparation technique. Table II summarizes the electrode fabrication parameters including the calculated (based on geometry) specific surface area and porosity of the perforated tube electrode.

The catalytic surface area is expected to be much greater than the geometric value shown in Table II because the $\mathrm{RuO}_{2}$ coating was deposited by thermal decomposition and therefore is highly porous. Reported catalytic surface areas for the DSA coating range up to 1000 times larger than the geometric area due to the roughness of the surface $(23,24)$. Thus, it is this porous coating that corresponds to the classical concept of a homogeneous porous electrode rather than the drilled holes of the titanium tube. Thus, the ratio of porosity and tortuosity for the porous coating would probably be larger than the geometric value for $\epsilon / \tau$ shown in Table II.

Also shown in Table II is the length of tube before the porous electrode $L_{\text {en }}$. This entrance length can be considered as the length available for the development of the hydrodynamic profile. The required entrance length is a function of the Reynolds number and it can be estimated (25)

$$
L_{\text {en }}=0.036 N_{R e}\left(2 r_{1}\right)
$$

At a Reynolds number of 100 , the entrance length from Eq. [35] is $1.64 \mathrm{~cm}$. The actual entrance length in the experiment was greater than this because Tygon tubing with an ID approximately equal to $r_{i}$ was used between the PVC pipe and the perforated tube electrode.

A saturated calomel electrode (SCE) was used as the reference electrode in the experiment and it was positioned downstream of the working electrode as shown in Fig. 3. The actual location (i.e., upstream or downstream) was unimportant because the conversion per pass was small; hence the reference electrode was bathed in a concentration with an essentially constant ratio of $\mathrm{Br}_{2} / \mathrm{Br}^{-}$throughout an experimental run. This constant concentration was used to calculate the null potential $\Delta U_{\mathrm{b}}$ which can be measured at open circuit. A measured value of $\Delta U_{\mathrm{b}}=0.757 \pm 0.0005 \mathrm{~V}$ was observed for all of the experimental data reported here. A calculated value of $\Delta U_{b}=0.772 \mathrm{~V}$ is predicted according to Eq. [12] with the concentrations of Table I. This discrepancy of $15 \mathrm{mV}$ between the observed and predicted values of $\Delta U_{b}$ may be attributable to the liquid junction potential between the reference electrode and the positive electrolyte which flowed by

Table II. Experimental back fed porous electrode fabrication parameters. (Values without superscripts were measured.)

\begin{tabular}{lll}
\hline Parameter & Value & Units \\
\hline$c / \tau$ & 0.1721 & none \\
$a$ & $112.4^{2}$ & $\mathrm{~cm}^{-1}$ \\
$L$ & 12.7 & $\mathrm{~cm}$ \\
$r_{m}$ & 0.3175 & $\mathrm{~cm}$ \\
$r_{1}$ & 0.2286 & $\mathrm{~cm}$ \\
$t$ & $0.00903^{8}$ & $\mathrm{~nm}^{3 / \mathrm{sec}}$ \\
$L_{\text {en }}$ & 12.7 & $\mathrm{~cm}^{3}$ \\
Electrode & 18.24 & $\mathrm{~cm}^{2}$ \\
area at $r_{1}$ & & \\
\hline
\end{tabular}

1 Assumed $T=1.0 ; \&$ was calculated from geometry of the holes in the perforated tube electrode.

2 Assumed value based on geometric specific surface area of $15.10 \mathrm{~cm}^{-1}$ and a roughness factor of 7.443 ,

${ }^{3}$ Calculated from assumed value of $\mu=1.25 \mathrm{~g} / \mathrm{cm}-\mathrm{sec}$ and a measured value of $\rho=1.384 \mathrm{~g} / \mathrm{cm}^{3}$. the SCE; (according to Ref. (26), liquid junction potentials can be on the order of $20 \mathrm{mV}$ ).

Membrane preparation.-The separator used in all experimental runs was a Nafion 315 membrane. The membrane was cut to the required width and then boiled in distilled water for at least $1 \mathrm{hr}$. The boiling was required to open the pores in the resin of the membrane and distilled water (instead of acid) was used to minimize the diffusion of $\mathrm{Br}_{2}$ through the Nafion as discussed in Ref. (27). The membrane was allowed to cool to room temperature and then it was wrapped around the outside of the porous electrode. The 0.6 to $0.3 \mathrm{~cm}$ seam where the membrane overlapped was glued by using a syringe applicator with an epoxy and hardener (General Electric No. 5.12 and No. 524). The glue was allowed to dry at room temperature for about 5 days. The electrode/membrane assembly was then tested for leaks with an approximate $30 \mathrm{~cm}$ static head of water. The membrane was wrapped tightly around the electrode and hence flow through the electrode (e.g., in one drilled hole and out another) was highly improbable; thus model Assumption e was fulfilled.

Electronics.-Figure 4 shows a schematic of the electrical connections used in the experiment. A Princeton Applied Research potentiostat (PAR 371) was used to control the first independent variable, the applied potential $V-\Phi_{\text {re }}$. That is, the potential difference between the porous electrode (i.e., the working electrode) and the SCE were controlled by adjusting the potential applied to the counterelectrode. The applied potential $V-\Phi_{\mathrm{re}}$ was not corrected for ohmic drop because the downstream reference electrode was located outside of the potential field which existed between the working electrode and the counterelectrode. Thus, it was assumed that the potential in the solution was the same everywhere in the flow channel and hence $\Phi_{\text {re }}=\Phi_{2}$. Thus, the total overpotential $\eta$ of Eq. [9] is related to the applied potential $V-\Phi_{2}=V-\Phi_{\text {re }}$ through the open circuit or null potential $\Delta \bar{U}_{\mathrm{b}}$ (i.e., $\eta=V-\Phi_{\mathrm{re}}-\Delta U_{\mathrm{b}}$ ). Also, the assumption of negligible potential drop within the porous region of the electrode implies that $\Phi_{r e}=\Phi_{2}=\Phi_{2,0}$. At a given applied potential and

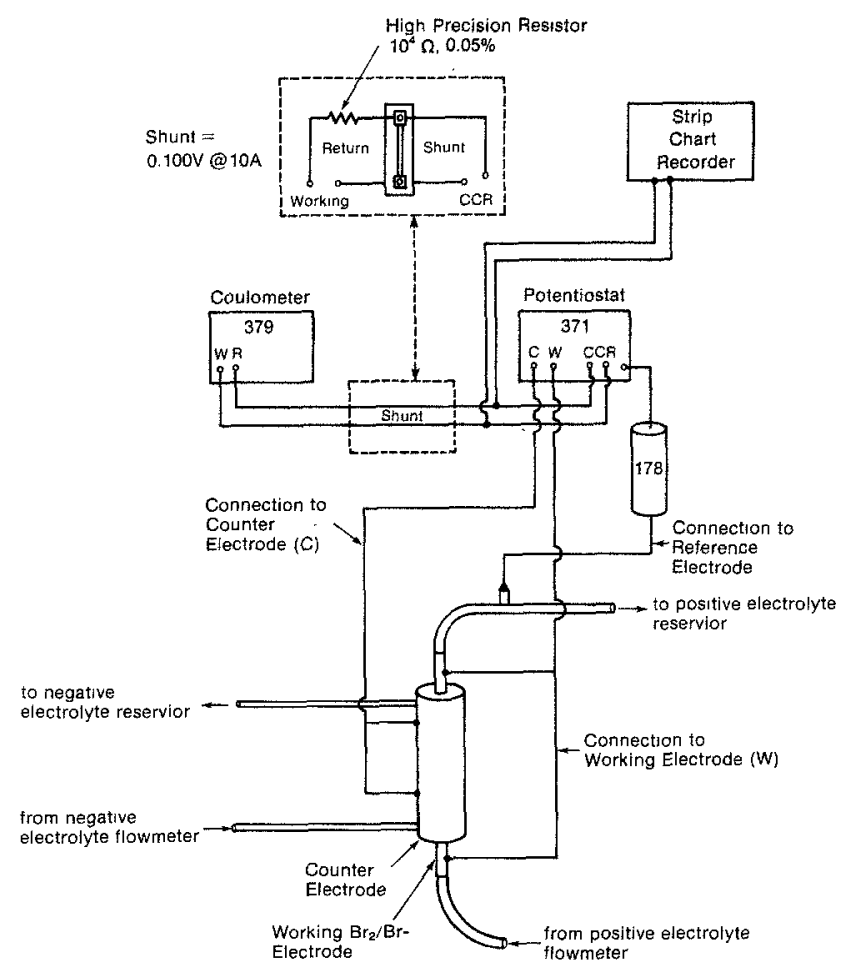

Fig. 4. A schematic of the experimental electronics 
Reynolds number, a strip chart recorder (as shown in Fig. 4) was used to verify that steady-state current conditions existed. This current was then read. from the analog meter on the PAR 371. The digital coulometer (PAR 379) shown in Fig. 4 was used to record the number of coulombs passed during an experimental run which was then used to calculate the faradaic conversion per pass of the positive electrolyte, as shown in Table I. (The coulometer was connected across a $10,000 \Omega$ shunt to reduce the input signal to within the limits of the coulometer.)

\section{Experimental Procedures}

Steady-state current measurement.-The procedure for measuring the steady-state current from the back fed electrode began by circulating the electrolyte streams for about an hour until the temperature of each stream was constant followed by an iodometric titration to find the initial $\mathrm{Br}_{2}$ concentration in the positive electrolyte. Once the bromine concentration was known, the cell was left at open circuit for 30 min and the null potential (i.e., the open-circuit potential between the working electrode and the downstream calomel reference electrode) $\Delta U_{\mathrm{b}}$ was recorded every $10 \mathrm{~min}$. Once the null potential was constant, experimental data were obtained; that is, a randomly chosen applied anodic potential difference $V-\Phi_{\text {re }}$ was set until a steady-state current was observed on the strip chart recorder. Then, the cell was returned to open circuit and the number of coulombs of charge were recorded. The null potential $\Delta U_{\mathrm{b}}$ as measured by the PAR 371 was recorded and the reservoir concentration of the $\mathrm{Br}_{2}$ above the titrated concentration was calculated by assuming $100 \%$ faradaic efficiency. This calculation was used to check the percent conversion.

If the percent conversion was small and if the null voltage was the same after the run as it was for the previous run, the cell was operated according to the above procedure at a randomly chosen cathodic potential difference. If the null potential was different from the value in the prior runs, the cell was charged or discharged at a low rate to adjust the bromine concentration, left at open circuit for $10 \mathrm{~min}$ and the null potential checked again. Then, samples were taken to determine the reservoir concentration of $\mathrm{Br}_{2}$ by titration. If the $\mathrm{Br}_{2}$ concentration was the same (to within $\pm 3 \%$ ) as the previous runs, the cell was operated at a randomly chosen cathodic potential difference according to the above procedure. Then, the above anodic/cathodic sequence was repeated.

Titration of these samples and the measurement of the null potential $\Delta U_{\mathrm{b}}$ were used to check the level of the bromine concentration $c_{2, b}$. Thus, the bromine concentration was not controlled during an experimental run but it was measured, and this measurement was used as a basis for including or discarding the results of an experimental data point. However, the titrations involved three $5 \mathrm{ml}$ samples from the reservoir volume which was about $3 \%$ of the reservoir volume. Therefore, to minimize additions to the reservoir, samples were taken and titrations were made after four or five experimental runs if the null potential was unchanged. Theoretically, the null potential can be used to predict changes in the bromine concentration to within $\pm 4 \%$ for a $0.5 \mathrm{mV}$ change at the concentrations shown in Table I. Experimentally, an observed change in $\Delta U_{\mathrm{b}}$ of $0.5 \mathrm{mV}$ corresponded to a $4 \%$ change in the bromine concentration as measured by titration of three samples. Thus, although the bromine concentration was not controlled in the experiment, the experimental error was approximately $4 \%$. To insure that these concentration errors were random, the experimental runs were randomized; hence, any concentration changes with time should not affect the average value of the measured current at a given applied potential and Reynolds number.
Flow control.-The second independent variable, the Reynolds number, was controlled by a needle valve as indicated by a flowmeter. That is, the volumetric flow in the nonporous region of the electrode was adjusted manually so that the Reynolds number remained constant for an experimental data point. The volumetric flow was obtained from a calibration curve which was drawn from manufacturers' data and the experimental kinematic viscosity shown in Table II. The density of the positive electrolyte was measured at $24^{\circ} \mathrm{C}$ and the viscosity of the electrolyte was obtained from Ref. (1) for this calculation. The approximate error in the experimental Reynolds number was $5 \%$.

\section{Experimental Results}

The points in Fig. 5 and 6 show the experimentally determined steady-state current as a function of applied potential and Reynolds number for the perforated tube back fed electrode. The numbers beside each data point correspond to the sequence in which the points were obtained. The data connected by dashed lines indicate the conditions where bubbles were observed in the exit stream. The solid lines in Fig. 5 and 6 are model predictions which are discussed below. The electrode fabrication parameters and electrolyte compositions are shown in Tables I and II. The electrolyte temperature for all data was $28^{\circ} \mathrm{C}$. The $\mathrm{Br}_{2}$ concentration varied by $3 \%$ from $0.0510 \mathrm{M}$ as shown in the figure but the null potential $\Delta U_{b}$ was essentially constant. The data were reproducible over the 2 month life of the experiment.

The general form of the results in Fig. 5 is similar to the behavior of a rotating disk electrode (RDE) as the rotation speed is increased; that is, the limiting current increases with Reynolds number and thereby shows a region in which external mass transfer controls the rate of reaction. Also, the length of the limiting current plateau decreases as the Reynolds number increases in a manner similar to an RDE system for

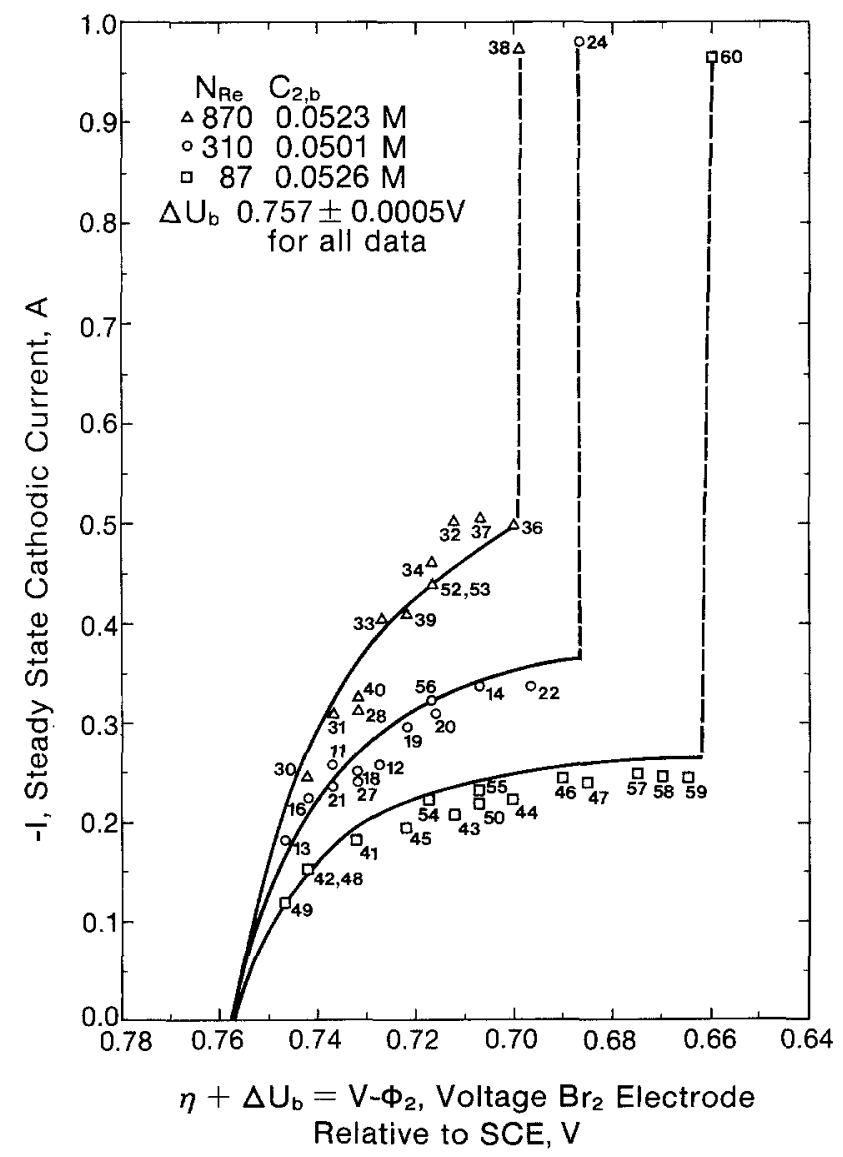

Fig. 5. Experimental cathodic steady-state currents 


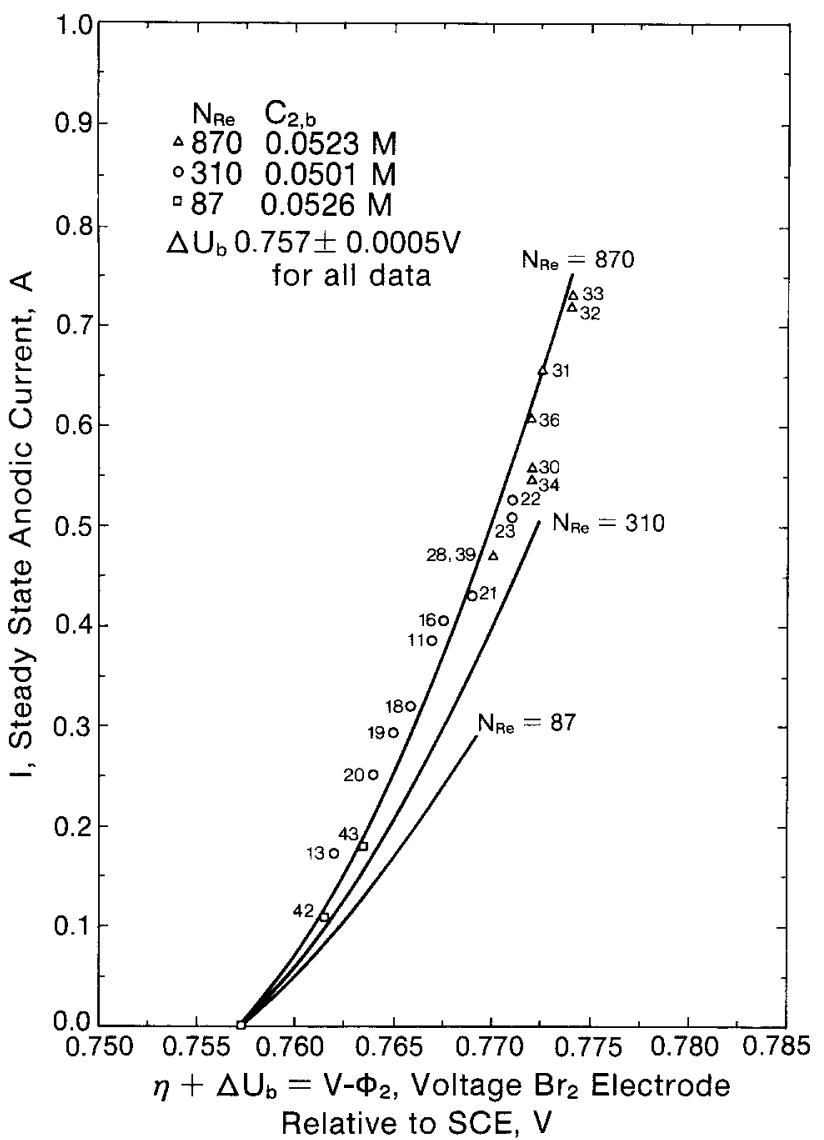

Fig. 6. Experimental anodic steady-state currents

the reduction of $\mathrm{Cu}^{+2}$ in acidic electrolyte (28). In Fig. 5, the side reaction characterized by gassing is probably the reduction of hydrogen ion. However, no changes in the $\mathrm{pH}$ of the positive electrolyte were noticed, but this could be a result of the small amount of gassing and the large reservoir.

The anodic experimental data in Fig. 6 depend only slightly on the Reynolds number over the range of experimentally applied potentials. This slight dependence is due to the high $\mathrm{Br}^{-}$concentration in the electrolyte $(20)$.

\section{Least Squares Regression}

The model presented above depends on, among other things, the parameters $\alpha_{\mathrm{c}}, i_{0}{ }^{\circ}$, and $D_{2}$. These parameters can be obtained from the literature if available (they are not available for these experimental conditions), determined by independent experiments or determined by applying least squares (LS) regression $(21,29-31)$ to the model and experimental data. Confidence is gained in the model if the parameter values obtained by LS are physically realistic. If the parameter values are physically realistic, extrapolation beyond the experimental range could be done within the limits of the assumptions. However, even if the parameter values are not physically realistic, LS does provide a set of parameter values suitable for use in the model which could be used for interpolation within the range of the experimental data. It is perhaps this last advantage of LS which is the most important for battery designers. That is, at the LS estimates the model provides the best functional relationship (for the assumed model) between the physical parameters and the experimental data. A better functional relationship may be obtained with a different model but in the absence of another model, the designer should use the LS estimates for interpolation even in preference to literature values.

The LS method consists of minimizing the following nonlinear objective function

$$
F(\beta)=\sum_{1} \epsilon_{1}^{2}=\sum_{1}\left(I_{1}-\hat{I_{1}}\right)^{2}
$$

where $\hat{I}_{1}=$ is given by Eq. [30] at the experimental conditions corresponding to the $1^{\text {th }}$ datum. The nonlinearity of Eq. [36] results from the nonlinear model equations, but it does not affect the theory behind LS regression. The computations necessary to minimize this objective function become more complicated with a nonlinear function; however, many computers have subroutine libraries which can perform the necessary calculations [see Ref. (20)]. The nonlinearity does affect the statistical inferences that can be made, and hence, the confidence limits for the parameters are valid only as the number of experimental data points becomes large (29). These confidence limits for the parameters are discussed in Ref. (20) and (32).

\section{Regression Results}

Table III presents the results of the application of the LS technique (20). As can be seen in Table III, in the first four cases $\alpha_{\mathrm{c}}$ was set and LS used to determine $i_{0}{ }^{\circ}$ and $D_{2}$, and in the last case LS was used to determine $\alpha_{\mathrm{c}}, \mathrm{i}_{\mathrm{o}}{ }^{\circ}$, and $D_{2}$. The solid lines shown in Fig. 5 and 6 were calculated according to Eq. [30] with the case five parameter values [no noticeable difference in the lines occurs when the case 3 or 4 Table III parameter values are used since the values of Eq. [36] are not significantly different (20)].

Quantitatively, the model predicts all of the experimental data points to within $30 \%$ and most of the data to within $10 \%$. The greatest deviations occur at large currents and Reynolds numbers; these deviations could be a result of measurement errors in either the flow rate or bulk $\mathrm{Br}_{2}$ concentration which are magnified at the large current experimental conditions. This degree of accuracy may be suitable for engineering purposes.

\section{Discussion}

Table IV presents a comparison of the LS parameter estimates with literature values. The LS estimate of the diffusion coefficient is the same order of magnitude as the published data which was obtained in a rotating disk experiment (33). The difference in diffusion coefficients may be attributable to the relatively small assumed value of $\varepsilon / \tau(0.172)$. That is, if it is assumed that the value for $D_{2}$ given by Osipov et al. (33) is correct, then $\epsilon / \tau$ for the porous electrode

Table III. Least squares estimates

\begin{tabular}{|c|c|c|c|c|c|}
\hline Case 1 & $\alpha c$ & $\alpha_{a^{2}}{ }^{2}$ & $\begin{array}{c}i_{0}{ }^{\circ} \times 10^{3}, \\
\mathrm{~A} / \mathrm{cm}^{2}\end{array}$ & $\begin{array}{l}D_{2} \times 10^{5} \\
\mathrm{~cm}^{2} / \mathrm{sec}^{2}\end{array}$ & $\mathrm{SSE}^{\mathrm{a}}$ \\
\hline $\begin{array}{l}1 \\
2 \\
3 \\
4 \\
5\end{array}$ & $\begin{array}{c}0.50 \\
0.75 \\
1.00 \\
1.50 \\
1.32 \pm 0.52\end{array}$ & $\begin{array}{l}1.50 \\
1.25 \\
1.00 \\
0.50 \\
0.68\end{array}$ & $\begin{array}{c}190 \pm 101 \\
610 \pm 63 \\
123 \pm 41 \\
58 \pm 17 \\
79 \pm 68\end{array}$ & $\begin{array}{l}(9.03 \pm 2.37) \\
(6.99 \pm 1.16) \\
(5.86 \pm 0.73) \\
(4.79 \pm 0.43) \\
(5.08 \pm 1.10)\end{array}$ & $\begin{array}{l}0.1386 \\
0.1076 \\
0.0965 \\
0.0925 \\
0.0919\end{array}$ \\
\hline
\end{tabular}

${ }^{1}$ Cases 1-4 are for $\alpha_{\mathrm{c}}$ fixed with $i_{0}{ }^{0}$, and $D_{2}$ the LS estimates. Case 5 is for $\alpha_{\mathrm{c}}, i_{\mathrm{o}^{\circ}}$, and $D_{2}$ as the LS estimates.

${ }^{2}$ Calculated from Eq. [81 with $n=2$.

${ }^{3} \mathrm{SSE}=$ value of Eq. [36] at LS estimates.

Table IV. Comparison of least sauares estimates with literature values for case 5 of Table III

\begin{tabular}{|c|c|c|c|}
\hline Parameter & Units & $\begin{array}{l}\text { Least squares } \\
\text { estimate }\end{array}$ & $\begin{array}{l}\text { Literature } \\
\text { value/Ref. }\end{array}$ \\
\hline$D_{\mathscr{2}}$ & $\mathrm{cm}^{2} / \mathrm{sec}$ & $\left(5.08 \underset{\times}{\frac{1}{10}} 1.10\right)$ & $1.2 \times 10=(33)$ \\
\hline $\begin{array}{l}i_{\mathrm{a}^{0}} \\
\alpha_{\mathrm{c}}\end{array}$ & $\underset{\text { none }}{\mathrm{A} / \mathrm{cm}^{2}}$ & $\begin{array}{c}0.079 \pm 0.068 \\
1.32 \pm 0.52\end{array}$ & $\begin{array}{c}0.345(33)^{1} \\
1.2(32) \dot{3} \\
1.24-1.57(35)\end{array}$ \\
\hline
\end{tabular}

${ }_{1} i_{o^{\circ}}$ extrapolated from the reported $i_{0, \mathrm{~b}}$ values using Eq. [5]. [8] and the LS estimate of $\alpha_{\mathrm{e}}=1.32$. 
studied here would be 0.728 . The point is that the product $\left(D_{2}\right)(\epsilon / \tau)$ (i.e., the effective diffusion coeffcient) is the unknown parameter in a porous electrode. The LS estimation procedure gives an estimate of $D_{2}$ which when multiplied by the assumed value of $\epsilon / \tau$ is suitable for design within the range of the data (2.e., for interpolation). The literature value for $i_{0}{ }^{\circ}$ is not directly comparable with the LS estimate in Table IV because the literature value was obtained on a platinum RDE whereas an $\mathrm{RuO}_{2}$ on Ti electrode was used here. However, the ISS estimate for $i_{0}{ }^{\circ}$ is reasonable because platinum should be a better catalyst and therefore result in a larger $i_{0}{ }^{\circ}$. Another complication in the comparison of $i_{0}{ }^{\circ}$ is that the product of the specific surface area $a$ and the exchange current density appears in the model and the value of $a$ was not measured in this experiment. However, the point is (as with the diffusion coefficient) the LS procedure gives an estimate of $i_{0}{ }^{\circ}$ which can be used in the model with the assumed value of $a$ to interpolate. It should be noted that the LS value of $i_{0}{ }^{\circ}$ gives a relatively large value of $i_{0, b}$ from Eq. [5] which is consistent with the observations of fast $\mathrm{Br}_{2} / \mathrm{Br}^{-}$kinetics by $\mathrm{Zn} / \mathrm{Br}_{2}$ battery designers $(1,4,6,7,34)$. The LS estimate of $\alpha_{c}$ agrees well with the literature values of Ref. (34) and (35). Both $i_{0}{ }^{\circ}$ and $\alpha_{\mathfrak{c}}$ have large error bounds due to the small amount of data obtained here for anodic polarizations (see Fig. 6) and for the lack of data on the concentration dependence of $\gamma_{\mathrm{i}}$. The model deviations from the experimental anodic data are also a result of the lack of data on the concentration dependence of $\gamma_{\mathrm{i}}$.

It is important to note that the model is sensitive to the parameter values throughout the range of the experimental data as demonstrated, for example, by Fig. 7 and 8. Similar predictions can be made for anodic currents $(20)$. It is also important to note that the estimated values of $i_{0}{ }^{\circ}$ and $D_{2}$ yield a small ellipse on a contour plot as shown in Fig. 9 with $\alpha_{c}=1.0$. Note that the minimum value of the objective appears as a steep narrow ellipse within the vicinity of the LS estimates (case 3, Table III).

With the value of $i_{a}{ }^{\circ}$ obtained by LS and the experimental concentrations, a large value of $B$ results from Eq. [19]. Thus, the model predicts a thin reaction zone as indicated in Fig. 10 by concentration changes only at the edge of the porous region. This implies that only a small fraction of the $\mathrm{RuO}_{2} / \mathrm{Ti}$ porous electrode is utilized even at relatively small overpotentials. Figure 10 illustrates an interesting feature of the model presented here. That is, at a given $\eta, \theta(\xi)$ drops rapidly over a small distance within the porous electrode to a constant value instead of zero as might be expected. The reason for this is the inclusion of the complete Butler-Volmer equation which leads to the $\Gamma$ term in Eq. [24] (20).

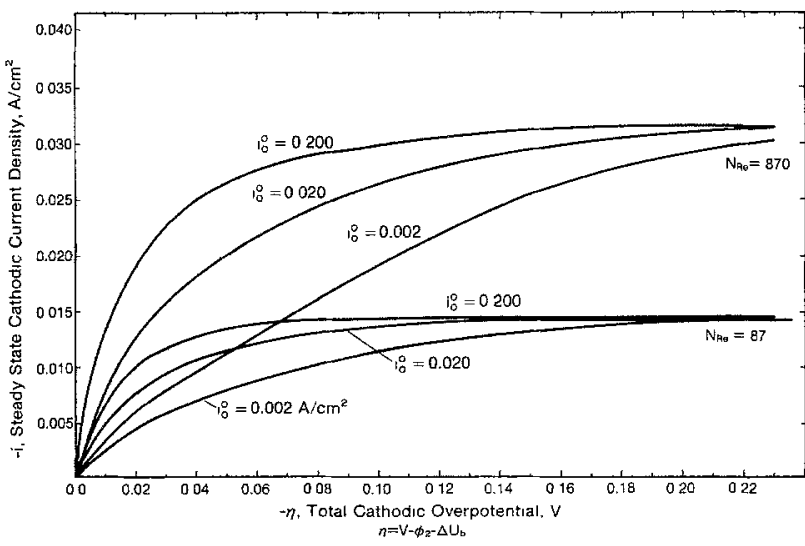

Fig. 7. Model sensitivity to changes in exchange current density for cathodic polarizations of case 5 of Table III values for $D_{2}$ and $\alpha_{c}$.

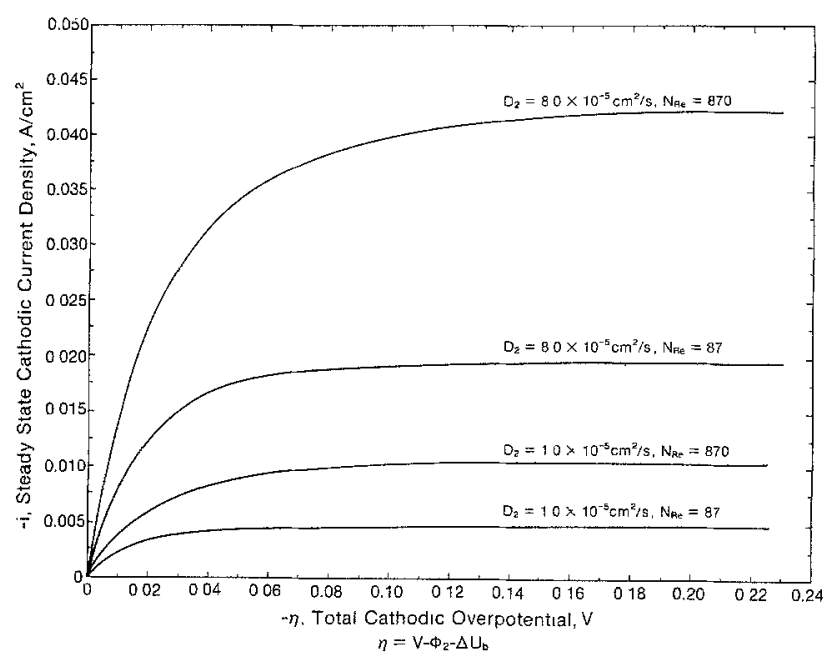

Fig. 8. Model sensitivity to change in the diffusivity for cothodic polarizations at case 5 of Table III values for $i_{0}{ }^{\circ}$ and $\alpha_{c}$.

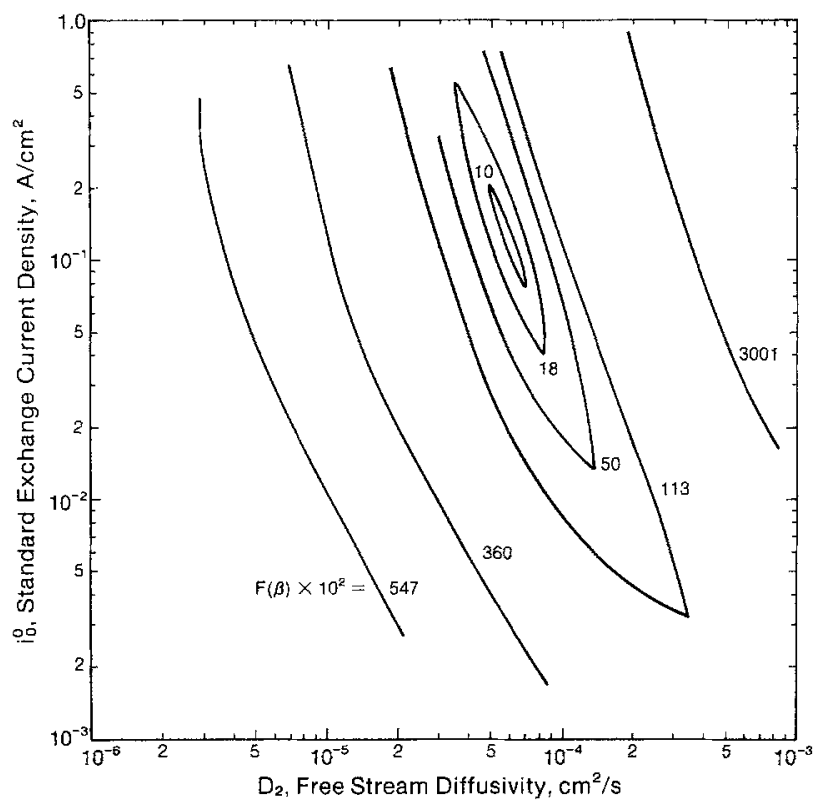

Fig. 9. Contours of the scaled least squares objective function $\left[\boldsymbol{F}(\beta)\right.$ (as given by Eq. $[36]$ ) $\left.\times 10^{2}\right]$ for $\alpha_{\mathrm{c}}=1.0$.

\section{Conclusions}

This study of a flow-by back fed porous electrode for the reduction of bromine produced a mechanistic model of the steady-state process. The model consists of a single analytical expression (Eq. [30]) suitable for design purposes. The model is applicable over a large range of overpotentials and includes external mass transfer resistance. Also, the model predicts most of the experimental data presented here to within approximately $10 \%$, and the parameter estimates of $\alpha_{\mathrm{c}}, i_{0}{ }^{\circ}$, and $D_{2}$ obtained here compare favorably with literature values.

Analysis of the flow-by back fed porous electrode for the reduction of bromine revealed that its limiting current is similar to a rotating disk; its limiting current density is characterized by a zero concentration at the surface on the side of the fresh reactant. The reaction zone for the fast reaction studied here is less than $5 \%$ of the electrode thickness; hence, the concentration profile is horizontal within the porous electrode and the reaction occurs on the back side of the electrode. This small reaction zone thickness indicates that small ohmic energy losses could be achieved by using thin back fed electrodes. The concentration profile shows that the $\mathrm{Br}_{2}$ concentration at the separator in a $\mathrm{Zn} / \mathrm{Br}_{2}$ battery could be reduced significantly 


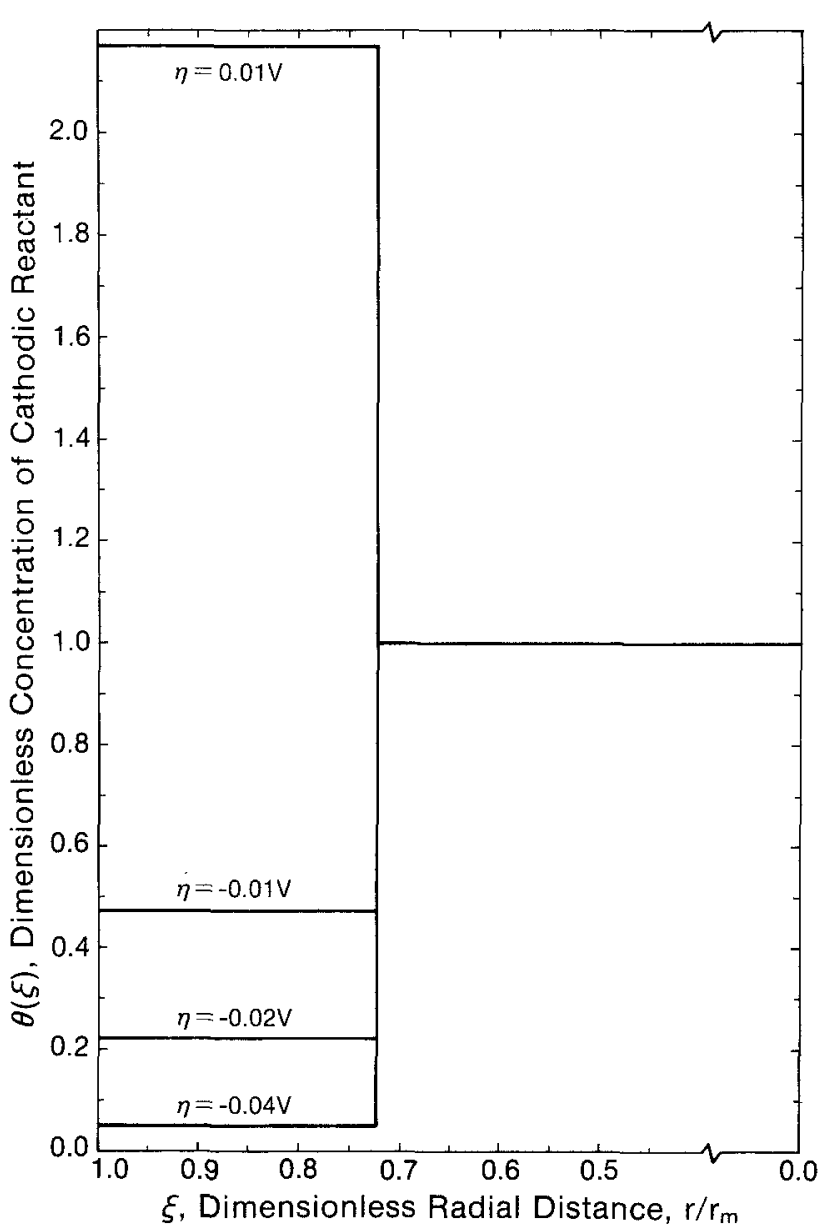

Fig. 10. Concentration profiles in experimental back fed porous electrode for LS parameter estimates of case 5 of Table III.

during discharge which would decrease the loss of $\mathrm{Br}_{2}$ across the separator. However, on charge, the concentration of $\mathrm{Br}_{2}$ at the separator would be increased and would cause consequently a greater loss of $\mathrm{Br}_{2}$.

\section{Acknowledgments}

This work was supported by the Center for Energy and Mineral Resources at Texas A\&M University. The electrode was coated with catalyst by the Chlor-Alkali Department of the Dow Chemical Company, Texas Division, Freeport, 'Texas. The experimental $\mathrm{Zn} / \mathrm{Br}_{2}$ reactor was furnished by Gould Incorporated, Rolling Meadows, Illinois. The authors gratefully acknowledge all of this support.

Manuscript submitted Nov. 16, 1982; revised manuscript received ca. May 13, 1983.

\section{APPENDIX}

The Back Fed Model in Cartesian Coordinates

The governing differential equation for the concentration of a cathodic reactant (e.g., bromine) which corresponds to Eq. [15] in the text is

$$
\frac{d^{2} c_{2}}{d x^{2}}-K c_{2}=\frac{-a i_{o, b}}{2 F D_{e}} \exp \left(\frac{\alpha_{n} \mathbf{F}}{R T} \eta\right)
$$

where

$$
K=\frac{a i_{0, \mathrm{~b}}}{2 \mathbf{F} D_{\mathrm{e}} c_{2, \mathrm{~b}}} \exp \left(\frac{-\alpha_{\mathrm{c}} \mathbf{F}}{R T} \eta\right)
$$

The following dimensionless variables can be used to simplify Eq. [A-1]

$$
\zeta=\frac{x}{x_{m}} ; \quad \theta=\frac{c_{2}}{c_{2, b}}
$$

Then, Eq. [A-1] becomes

$$
\frac{d^{2} \theta}{d \xi^{2}}-B \theta=-A
$$

where

$$
A=\frac{a i_{0, b} x_{m}{ }^{2}}{2 F D_{\mathrm{e}} c_{2, b}} \exp \left(\frac{\alpha_{\mathrm{a}} F}{R T} \eta\right)
$$

and

$$
B=K x_{\mathfrak{m}^{2}}
$$

The boundary conditions are at

$$
x=x_{\mathrm{m}}, \quad \zeta=1.0, \quad \frac{d \theta}{d \zeta}=0
$$

at

$$
x=0, \quad \zeta=0, \quad \frac{d \theta}{d \zeta}=\frac{x_{\mathrm{m}} k}{D_{\mathrm{e}}}(\theta(0)-1.0)[\mathrm{A}-8]
$$

where

$$
k=1.651 \frac{D_{2}}{2 r_{\mathrm{h}}}\left(1.5 N_{\mathrm{Re}} N_{\mathrm{Se}} \frac{2 r_{\mathrm{h}}}{L}\right)^{1 / 3}
$$

and $r_{\mathrm{h}}$ is the hydraulic radius as defined in Ref. (25).

Equation [A-4] can be solved analytically by assuming a solution of the form

$$
\theta(\zeta)=\Psi(\zeta)+\Gamma
$$

where $\Gamma$ is a constant at a given $\eta$ and temperature and is given by

$$
\Gamma=\exp \left(\frac{2 \mathbf{F}}{R T} \eta\right)
$$

The general form of $\Psi(\zeta)$ is

$$
\Psi(\zeta)=E \sinh (\sqrt{B} x)+F \cosh (\sqrt{B} x)
$$

and application of boundary condition Eq. [A-7] gives

$$
F=-E \operatorname{coth}\left(\sqrt{B} x_{m}\right)
$$

Application of boundary condition Eq. [A-8] gives

$$
E=\frac{x_{\mathrm{m}} k}{D_{\mathrm{e}} \sqrt{B}}(\theta(0)-1.0)
$$

Thus, the complete solution for $\theta(\zeta)$ is

$$
\begin{array}{r}
\theta(\zeta)=E \sinh (\sqrt{B} \zeta)-E \operatorname{coth}\left(\sqrt{B} x_{\mathfrak{m}}\right) \\
\cosh (\sqrt{B} \zeta)+\exp \left(\frac{2 \mathbf{F}}{R T} \eta\right)
\end{array}
$$

Solving for the unknown surface concentration, $\theta(0)$, in Eq. [A-13] gives

$$
\theta(0)=\frac{x_{\mathrm{m}} k \operatorname{coth}\left(\sqrt{B} x_{\mathrm{m}}\right)+D_{\mathrm{e}} \sqrt{B} \exp \left(\frac{2 \mathbf{F}}{R T} \eta\right)}{D_{\mathrm{e}} \sqrt{\bar{B}}+x_{\mathrm{m}} k \operatorname{coth}\left(\sqrt{B} x_{\mathrm{m}}\right)}
$$

Now, consideration of the case where $\sqrt{B} \rightarrow 100.0$ gives

$$
\theta(0)=\frac{x_{\mathrm{m}} k+D_{\mathrm{e}} \sqrt{\bar{B}} \exp \left(\frac{2 \mathbf{F}}{R T} \eta\right)}{x_{\mathrm{m}} k+D_{\mathrm{e}} \sqrt{\bar{B}}}
$$

Finally, an expression for the current density is

$$
\frac{i}{2 \mathbf{F}}=\left.N_{2}\right|_{x=0}=k c_{2 b}(\theta(0)-1.0)
$$

where $\theta(0)$ is defined by Eq. [A-16] or [A-17].

\section{LIST OF SYMBOLS}

a specific catalytic surface area of porous electrode, $\mathrm{cm}^{-1}$

$c_{1}, c_{2}$ concentration of $i^{\text {th }}$ species, $i=2$ for bromine, $\mathrm{mol} / \mathrm{cm}^{3}$

$c_{i, b}, c_{2, b}$ bulk concentration of $i^{\text {th }}$ species, $i=2$ for

bromine, $\mathrm{mol} / \mathrm{cm}^{3}$

$c_{i}{ }^{\circ} \quad$ standard reference concentration of $i^{\text {th }}$ species $=10^{-3} \mathrm{~mol} / \mathrm{cm}^{3}$

$c_{i, \text { re }}$ reference electrode concentration of $i^{\text {th }}$ species, $\mathrm{mol} / \mathrm{cm}^{3}$ 
$D_{B} \quad$ effective diffusion coefficient of bromine, $\mathrm{cm}^{2} /$ sec

$D_{2} \quad$ free stream diffusion coefficient of bromine, $\mathrm{cm}^{2} / \mathrm{sec}$

F faraday's constant, $96,487 \mathrm{C} / \mathrm{mol}$ of electrons

$F(\beta) \quad$ least squares objective function, $\mathrm{A}^{2}$

$I$ total cell current, $A$

$I_{0}(\cdot)$ modified Bessel function of the first kind, zero order

$I_{1}(\cdot)$ modified Bessel function of the first kind, first order

$I_{1} \quad$ lth experimentally observed current, A

$\hat{I}_{1}$ model predictions at experimental conditions corresponding to the 1 th datum, $A$

$i$ steady-state current density, $\mathrm{A} / \mathrm{cm}^{2}$

$i_{\mathrm{L}} \quad$ limiting current density, $\mathrm{A} / \mathrm{cm}^{2}$

$i_{0, b}$ exchange current density at bulk concentrations, $\mathrm{A} / \mathrm{cm}^{2}$

$i_{0}{ }^{\circ} \quad$ standard exchange current density at $1 M, A /$ $\mathrm{cm}^{2}$

$j_{\mathrm{i}} \quad$ average production rate per unit area

K reaction rate function, $\mathrm{cm}^{-2}$

$K_{\mathrm{o}}(\cdot)$ modified Bessel function of the second kind, zero order

$K_{1}(\cdot)$ modified Bessel function of the second kind, first order

$k$ mass transfer coefficient, $\mathrm{cm} / \mathrm{sec}$

$L$ electrode length, $\mathrm{cm}$

$L_{\text {en }} \quad$ entrance length, cm (see Eq. [35])

$N_{\mathrm{i}}, N_{2}$ flux of $\mathrm{i}^{\text {th }}$ species, $i=2$ for bromine, mol/ $\mathrm{cm}^{2} / \mathrm{sec}$

$N_{\text {Re }} \quad$ Reynolds number

$N_{\text {Se }} \quad$ Schmidt number

$n$ number of mols of electrons ( $n=2$ mols of electrons for reaction [1])

$p_{\mathbf{i}}, q_{\mathbf{i}}$ reaction orders for $\mathrm{i}^{\mathrm{th}}$ species $\left(p_{\mathrm{Br}-}=\mathbf{2}\right.$, $q_{\mathrm{Br} 2}=1$ )

$R \quad$ gas constant, $8.313 \mathrm{~J} / \mathrm{mol} / \mathrm{K}$

$r \quad$ radial coordinate, $\mathrm{cm}$

$r_{j} \quad$ inside radius of electrode, $\mathrm{cm}$

$r_{\mathrm{m}}$ membrane radius, $\mathrm{cm}$

$s_{i} \quad$ stoichiometric coefficient of $i^{\text {th }}$ species $\left(s_{\mathrm{Br}}-\right.$ $\left.=2, s_{\mathrm{Br} 2}=-1\right)$

$T \quad$ temperature, $K$

$U^{\theta} \quad$ standard open circuit potential of working electrode, $\mathrm{V}$

$U_{\mathrm{re}^{\theta}} \quad$ standard reference electrode potential, $\mathrm{V}$

$\mathrm{V}$ potential of working electrode, $\mathrm{V}$

$v$ axial velocity behind the back fed electrode, $\mathrm{cm} / \mathrm{sec}$

Greek letters

$\alpha_{a} \quad$ apparent anodic transfer coefficient

$\alpha_{\mathrm{c}} \quad$ apparent cathodic transfer coefficient

$\beta \quad$ vector of least squares parameters, $=\left[\begin{array}{ll}i_{0}{ }^{\circ} & D_{2}\end{array}\right.$ $\left.\alpha_{c}\right]$

$\gamma_{i}$ concentration dependence for exchange current density

porosity of electrode

$\epsilon$ lth residual of least squares function, $A$

$\eta$ total overpotential, $V$

$\theta(\mathrm{t}) \quad$ dimensionless surface concentration

$\nu$ kinematic viscosity, $\mathrm{cm}^{2} / \mathrm{sec}$

$\xi$ dimensionless radial coordinate

$\pi \quad 3.1416$

$\tau$ tortuosity of porous electrode

Tre potential in the solution at the reference electrode, $\mathrm{V}$

\$2 potential of the solution in flow channel of porous electrode, $\mathrm{V}$

$\Phi_{2,0} \quad$ potential of the solution just outside the double layer, $V$

\section{REFERENCES}

1. R. A. Putt, "Assessment of Technical and Economic Feasibility of Zinc-Bromine Batteries for Utility Load Leveling", Final Report to Electric Power Research Institute, Palo Alto, CA, EM-1059, Research Project 635-1, May 1979.

2. P. Y. Lu, Workshop on Electrodes for Flowing Solution Batteries, summary by $L$. Nanis for Electric Power Research Institute, Palo Alto, CA, Special Study Project WS-79-192, Section 2, Feb. 1981.
3. D. J. Eustace, This Journal, 127, 528 (1980).

4. F. G. Will, C. D. Iacovangelo, J. S. Jackowski, and F. W. Secor, "Assessment of the Zinc-Bromine Battery for Utility Load Leveling," Final Report to U.S. Dept. of Energy, Division of Energy Storage Systems, Contract No. 2950, EY-76-C-022950, N Varch 1978.

5. B. V. Tilak, P. W. T. Lu, J. E. Colman, and S. Srinivasan, in "Comprehensive Treatise of Electrochemistry," Vol. 2, J. O'M. Bockris, B. E. Conway, E. Yeager, and R: E. White, Editors, p. 63, Plenum Press, New York (1981).

6. R. Bellows, D. Estace, P. Grimes, I. Shropshire, and H. Tslen, in 11th International Power Sources Symposium, p. 301, Brighton, England, Sept. 1978.

7. R. Bellows, H. Einstein, P. Grimes, E. Kanter, and K. Newby, in 15th Intersociety Energy Conversion Engineering Conference, Seattle, WA, p. 1465-1470, Aug. 1980.

8. J. S. Newman and C. W. Tobias, This Journal, 109, 1183 (1962).

9. I. G. Gurevich and V. S. Bagotskii, Electrochim. Acta, 9, 1151 (1964).

10. O. S. Ksenzhek, Zh. Fiz. Khim., 36, 633 (1962).

11. E. A. Grens and C. W. Tobias, Electrochim. Acta, 10, 761 (1965).

12. L. G. Austin and H. Lerner, ibid., 9, 1469 (1964).

13. J. Newman and W. Tiedeman, AIChE J., 21, 25 (1975).

14. J. O'M. Bockris and S. Srinivasan, "Fuel Cells: Their Electrochemistry," p. 234, 254, 256, McGraw Hill, New York (1969).

15. B. V. Tilak, R. S. Yeo, and S. Srinivasan, in "Comprehensive Treatise of Electrochemistry," Vol. 3, J. O'M. Bockris, B. E. Conway, E. Yeager and R. E. White, Editors, p. 70, Plenum Press, New York (1981).

16. J. A. Trainham, Ph.D. Dissertation, University of California, Berkeley, CA (1979).

17. J. Newman, "Electrochemical Systems", p. 174 Prentice-Hall, Inc., Englewood Cliffs, NJ (1973).

18. J. Newman, "Electrochemical Systems," PrenticeHall, Inc., Englewood Cliffs, NJ (1973).

19. H. S. Mickely, T. K. Sherwood, and C. E. Reed "Applied Mathematics in Chemical Engineering," 2nd ed., p. 197, McGraw-Hill, New York (1957).

20. J. Van Zee, M. S. Thesis, Texas A\&M University, College Station, TX (1982).

21. B. Ostle and R. W. Mensing, "Statistics in Research," 3rd ed., pp. 166-178, Iowa State University Press, Ames, Iowa (1975).

22. R. D. Weaver, "Testing and Evaluation Results of Gould Laboratory Prototype Zinc Bromine Cells," Final Report to Electric Power Research Institute, p. 56, Palo Alto, CA, Dec. (1977).

23. P. C. S. Hayfield and W. R. Jacob, in "Modern Chlor-Alkali Technology," M. O. Coulter, Editor, p. 105, Ellis Horwood Ltd., Chichester, West Sussex, England (1980).

24. D. L. Caldwell and $M$. J. Hazelrigg, in "Modern Chlor-Alkali Technology," M. O. Coulter, Editor, p. 127, Ellis Horwood, Ltd., Chichester, West Sussex, England (1980).

25. R. B. Bird, W. E. Stewart, and E. N. Lightfoot, "Transport Phenomena," p. 47, John Wiley, New York (1960).

26. J. Newman, "Electrochemical Systems," p. 130 , Prentice-Hall, Inc., Englewood Cliffis, NJ (1973).

27. F. Will, This Journal, 126, 36 (1979).

28. R. White and J. Newman, J. Electroanal. Chem., 82, 176 (1977)

29. W. J. Kennedy, Jr. and J. E. Gentle, "Statistical Computing," p. 426, MarceI Decker, Inc., New York (1980).

30. Y. Bard, "Nonlinear Parameter Estimation," Academic Press, New York (1974).

31. R. J. Freund and P. D. Minton, "Regression Methods," Marcel Decker, Inc., New York (1979).

32. A. R. Gallant, Am. Stat,, 29, 73 (1975).

33. O. R. Osipov, M. A. Novitiskii, Yu. M. Povarov, and P. D. Lukovtsev, Elektrokhimiya, 8, 327 (1972).

34. F. Will, in 11 th International Power Sources Symposium, p. 9, Brighton, England, Sept. 1978; Personal communication with F. Will, July 2, 1982.

35. I. Rubinstein, J. Phys. Chem., 85, 1899 (1981). 